\title{
Association between coronary dominance and acute inferior myocardial infarction: a matched, case-control study
}

\author{
$\mathrm{Li} \mathrm{Wang}^{1+}$, Jiamei $\mathrm{Li}^{1+}, \mathrm{Ya}$ Gao${ }^{1}$, Ruohan $\mathrm{Li}^{1}$, Jingjing Zhang ${ }^{1}$, Dan Su${ }^{2}$, Tao Wang ${ }^{3}$, Guang Yang ${ }^{4}$ and \\ Xiaochuang Wang ${ }^{1 *}$ (D)
}

\begin{abstract}
Background: Previous studies have found a connection between left coronary artery dominance and worse prognoses in patient with acute coronary syndrome, which remains a predominant cause of morbidity and mortality globally. The aim of this study was to investigate whether coronary dominance is associated with the incidence of acute inferior myocardial infarction (MI).

Methods: Between January 2011 and November 2014, 265 patients with acute inferior Ml and 530 age-matched and sex-matched controls were recruited for a case-control study in the Second Affiliated Hospital of Xi'an Jiaotong University in Xi'an, China. All participants underwent coronary angiography. The exclusion criteria included history of coronary artery bypass graft surgery, chronic or systemic diseases (including hepatic failure, kidney failure, hypothyroidism and Grave's disease), ventricular fibrillation, and known allergy to iodinated contrast agent. Patients with left- or co-dominant anatomies were placed into the LD group and those with right-dominant anatomy were included in the RD group. The association of acute inferior Ml and coronary dominant anatomy were assessed using multivariable conditional logistic regression, and to estimate the odds ratio (OR) and 95\% confidence interval (95\%Cl).

Results: Distributions of right dominance were significantly different between the acute inferior Ml group and control group (94.0\% vs. 87.9\%, $P=0.018)$. Univariable conditional logistic regression revealed that right dominance may be a risk factor for the incident acute inferior MI (OR: 2.137; 95\% Cl: 1.210-3.776; $P=0.009)$. After adjusting for baseline systolic blood pressure, heart rate, smoking status, diabetes mellitus, hypertension, hyperlipidaemia, and family history of coronary artery disease, results of multivariate conditional logistic regression showed that right dominance was associated with the incidence of acute inferior MI (OR: 2.396; 95\% Cl: 1.328-4.321; $P=0.004)$.
\end{abstract}

Conclusions: Right coronary dominance may play a disadvantageous role in the incidence of acute inferior MI. However, further studies are needed to verify our findings, especially with regard to the underlying mechanisms.

Keywords: Coronary dominance, Acute inferior myocardial infarction, Case-control study, Coronary angiography

\section{Background}

Acute myocardial infarction (MI) is the most serious manifestation of coronary artery disease, and it remains a predominant cause of morbidity and mortality globally $[1,2]$. It has been widely recognised that hypertension, diabetes, smoking, abnormal lipid levels, obesity, alcohol

\footnotetext{
* Correspondence: dr_xc_wang@163.com

${ }^{+} \mathrm{Li}$ Wang and Jiamei Li contributed equally to this work.

'Department of Critical Care Medicine, the Second Affiliated Hospital of Xi'an Jiaotong University, Xi'an, China

Full list of author information is available at the end of the article
}

abuse, physical activity, and psychosocial factors account for most cases of MI [3, 4]. Inferior MI occurs in 40-50\% of all cases of acute MI, mainly due to right coronary artery (RCA) or left circumflex coronary artery (LCx) occlusion [5]. Inferior MI is prone to be silent but complicated with heart block, right ventricular infarction, and concomitant pericardial ST-segment depression. Myocardial perfusion of the RCA and LCx is strongly influenced by coronary dominance, which implicates the vulnerability of different branches of the coronary artery $[6,7]$.

(c) The Author(s). 2019 Open Access This article is distributed under the terms of the Creative Commons Attribution 4.0 International License (http://creativecommons.org/licenses/by/4.0/), which permits unrestricted use, distribution, and reproduction in any medium, provided you give appropriate credit to the original author(s) and the source, provide a link to the Creative Commons license, and indicate if changes were made. The Creative Commons Public Domain Dedication waiver (http://creativecommons.org/publicdomain/zero/1.0/) applies to the data made available in this article, unless otherwise stated. 
The coronary artery is a main part of the circulatory system, and it provides the heart with nutrients and oxygen. According to the blood supply of the posterior interventricular septum, coronary circulation is categorised as right dominance, left dominance, and co-dominance $[6,8]$. Right dominant anatomy is most prevalent (approximately 70-86\%), whereas left dominance occurs in about $8-13 \%$ of cases and co-dominance is present in $4-18 \%$ of cases [9-11]. The overwhelming majority of research has focused on the role of the left dominant coronary system in coronary artery disease (CAD), and several studies have shown that left dominance is closely associated with acute coronary syndrome (ACS) and significant CAD [12-15]. However, our pilot study of 2225 patients with CAD indicated that right dominant anatomy tends to be associated with right coronary artery stenosis and multivessel coronary vascular lesions. We further observed that compared to patients with left dominance, those with right dominance were more prone to have inferior MI. Therefore, we hypothesize that there is a potential link between right coronary dominance and inferior MI. The aim of this study was to explore whether patients with right dominant anatomy have a higher incidence of acute inferior MI.

\section{Materials and methods}

\section{Study design and population}

We conducted a hospital-based, matched, case-control study based on Northern Chinese population. All patients with acute inferior MI (including STEMI and NSTEMI) were diagnosed for the first time in the emergency department from January 2011 to November 2014. The diagnosis of acute inferior MI relied on biomarker evidence of myocyte necrosis, coronary angiography (CAG), electrocardiographic and ischaemic symptoms [1]. Control participants (without luminal narrowing) obtained from the CAG Service Database of the Second Affiliated Hospital of Xi'an Jiaotong University. We recruited 1164 patients undergoing CAG according to our inclusion and exclusion criteria (Fig. 1). Eventually, 265 patients with inferior MI and 530 controls, age-matched and sex-matched individuals (2 individuals per patients with acute inferior $\mathrm{MI}$ ), were included in the final analysis. All of the examinations were carried out for diagnosis of MI according to guidelines from the European Society of Cardiology [16]. All the patients were referred due to standard indications that have been shown to use CAG for appropriate clinical circumstances.

Hypertension was defined as office blood pressure $\geq$ $140 / 90 \mathrm{mmHg}$ or $24-\mathrm{h}$ ambulatory blood pressure $\geq$ $135 / 85 \mathrm{mmHg}$ [16]. A haemoglobin A1c value $\geq 6.5 \%$, previous criteria for fasting glucose $\geq 126 \mathrm{mg} / \mathrm{dL}$, or 2 -h glucose level $\geq 200 \mathrm{mg} / \mathrm{dL}$ were used to diagnosis diabetes mellitus [17]. A current smoking was defined as a person who smoked at least one cigarette per day and had smoked for at least 1 year [18]. Dyslipidaemia was defined as a total cholesterol level $\geq 200$ $\mathrm{mg} / \mathrm{dL}$, triglyceride level $\geq 150 \mathrm{mg} / \mathrm{dL}$, low-density lipoprotein level $\geq 130 \mathrm{mg} / \mathrm{dL}$, or high-density lipoprotein level $\leq 40 \mathrm{mg} / \mathrm{dL}$ [19].

\section{Coronary angiography}

CAG was performed in all patients through radial or femoral access using a standard clinical technique [20]. CAD was defined as luminal narrowing $\geq 50 \%$ on a coronary angiogram. Significant stenosis was defined as $\geq 50 \%$ luminal narrowing of the epicardial coronary arteries. Right dominant anatomy was defined when the posterior descending artery (PDA) originated from the RCA. Left dominant anatomy was defined when the PDA originated from the LCx. Co-dominant anatomy was defined when the PDA originated from the RCA and a large posterolateral branch originated from the LCx reached near the posterior interventricular groove $[21,22]$. Patients with left- or co-dominant anatomies were placed into the LD group and those with right-dominant anatomy were included in the RD group.

\section{Statistical analysis}

Descriptive statistics are presented as percentages for discrete variables and as a mean \pm standard deviation for continuous variables. Bivariate comparisons between patients with and without acute inferior MI were performed using the t-test and chi-square test, respectively. A conditional logistic regression model was used to analyse the relationship between acute inferior $\mathrm{MI}$ and coronary dominant anatomy. After adjusting for right dominance, baseline systolic blood pressure (SBP), heart rate, smoking status, diabetes mellitus, hypertension, hyperlipidaemia, and family history of CAD, multivariable conditional logistic regression was performed to identify independent risk factors, and to estimate the odds ratio (OR) and 95\% confidence interval (95\%CI). Furthermore, we conducted subgroup analyses using multivariate logistic regression models to identify interactions between acute inferior MI and clinically relevant factors by comparing models with and without multiplicative interaction terms. $P$-values were two-tailed and considered statistically significant at $<0.05$. All statistical analyses were conducted using $\mathrm{R}$ software (version 3.1.3).

\section{Results}

\section{Participants' characteristics}

All participants' baseline characteristics are shown in Table 1. No significant differences in age and sex were found between the cases and controls after adequate matching. Smoking (63.4\% vs. 50.9\%) and diabetes 


\begin{tabular}{l}
$\begin{array}{l}\text { Participants were obtained from the Second Affiliated Hospital of Xi'an } \\
\text { Jiaotong University in Northern China from January } 2011 \text { to November } 2014 \\
(n=2225)\end{array}$ \\
$\qquad \begin{array}{l}\text { Inclusion criteria: } \\
\text { 1. Over 18 years old } \\
\text { 2. Cases were first-ever acute myocardial infarction } \\
\text { 3. Controls were undergoing CAG and stenosis of coronary } \\
\text { artery<30\% } \\
4: \text { Completed CAG data medical records } \\
\text { Exclusion criteria: } \\
\text { 1. Previous coronary artery bypass graft surgery } \\
\text { 2. Ventricular fibrillation } \\
\text { 3. History of chronic or systemic diseases (including hepatic } \\
\text { failure, kidney failure, hypothyroidism and Grave's disease) } \\
\text { 4. Known allergy to iodinated contrast agent }\end{array}$ \\
\hline
\end{tabular}

Met inclusion criteria $(\mathrm{n}=1164)$

Case patients: 265

Control participants: 899

Eligible participants for the study (Matched 1:2, $\mathrm{n}=795$ )
Case patients: 265
Control participants: 530

Fig. 1 Flow diagram of patient selection. 265 patients with acute inferior myocardial infarction and 530 age-matched and sex-matched controls were recruited in the study

mellitus $(23.0 \%$ vs. $11.7 \%)$ were observed more frequently in patients with acute inferior MI. The proportions of right dominant anatomy were $94.0 \%$ in the acute inferior MI group and $88.8 \%$ in the control group in the unmatched dataset $(P=0.033)$. Furthermore, patients with acute inferior MI (94.0\%) had a higher percentage of right dominant anatomy than the control group $(87.9 \%)$ in the matched dataset $(P=0.018)$. Moreover, there was no statistically significant difference between cases and controls in the baseline SBP, heart rate, hypertension, hyperlipidaemia, and family history of CAD.

\section{CAG results of patient with acute inferior $\mathrm{MI}$}

Our study further investigated the CAG results of 265 patients with acute inferior MI in different dominance groups. No statistically significant difference was found in the demographics, presence of diabetes mellitus, presence of hypertension, smoking status, family history of CAD, and location of significant stenosis in patients with right dominant anatomy compared to those with left dominant anatomy (Table 2).

\section{Association between acute inferior Ml and right coronary artery dominance}

In univariate analysis, the risk factors related to the presence of acute inferior MI were right dominance (OR: 2.137; 95\%CI: $1.210-3.776 ; P=0.009$ ), smoking (OR: 1.668; 95\% CI: $1.233-2.257 ; P=0.001$ ), and diabetes mellitus (OR: 2.257; 95\%CI: $1.528-3.333 ; P<0.001$ ). In further multivariate conditional logistic regression analysis, right dominance was closely related to the occurrence of acute inferior MI (OR: 2.396; 95\%CI: 1.328-4.321; $P=0.004)$ after adjusting for baseline SBP, heart rate, smoking status, diabetes mellitus, hypertension, hyperlipidaemia, and family history of CAD (Table 3).

\section{Subgroup analyses}

In addition, we performed a subgroup analysis to further confirm the role of right dominance in the occurrence of acute inferior MI in different circumstances. We found that associations between acute inferior MI and coronary dominance were similar in the subgroups. There was no significant interaction by age ( $<60$ years old vs. $\geq 60$ years old), sex (female vs. male), baseline SBP $(<160 \mathrm{mmHg}$ vs. $\geq 160 \mathrm{mmHg})$, heart rate $(<70$ beats/minute [bpm] vs. 
Table 1 Baseline characteristics of patients

\begin{tabular}{|c|c|c|c|c|c|c|}
\hline \multirow[t]{2}{*}{ Clinical variables } & \multicolumn{3}{|c|}{ Unmatched (complete) dataset } & \multicolumn{3}{|l|}{ Matched (1:2) dataset } \\
\hline & Inferior MI $(n=265)$ & Control $(n=899)$ & $P$ & Inferior MI $(n=265)$ & Control $(n=530)$ & $P$ \\
\hline Age (years) & $58.8 \pm 11.4$ & $58.1 \pm 9.8$ & 0.364 & $58.8 \pm 11.4$ & $58.6 \pm 10.7$ & 0.816 \\
\hline Sex, n (\%) & & & $<0.001$ & & & 1.000 \\
\hline Female & $34(12.8)$ & $365(40.6)$ & - & $34(12.8)$ & $68(12.8)$ & - \\
\hline Male & $231(87.2)$ & $534(59.4)$ & - & $231(87.2)$ & $462(87.2)$ & - \\
\hline Baseline SBP (mmHg) & $128.8 \pm 22.5$ & $131.3 \pm 30.3$ & 0.143 & $128.8 \pm 22.5$ & $130.6 \pm 31.8$ & 0.345 \\
\hline Heart rate (bpm) & $74.9 \pm 14.6$ & $72.6 \pm 19.3$ & 0.045 & $74.9 \pm 14.6$ & $75.9 \pm 15.5$ & 0.376 \\
\hline \multicolumn{7}{|l|}{ CAD risk factors, $\mathrm{n}(\%)$} \\
\hline Smoking & $168(63.4)$ & $318(35.4)$ & $<0.001$ & $168(63.4)$ & $270(50.9)$ & 0.001 \\
\hline Diabetes & $61(23.0)$ & $91(10.1)$ & $<0.001$ & $61(23.0)$ & $62(11.7)$ & $<0.001$ \\
\hline Hypertension & $124(46.8)$ & $458(50.9)$ & 0.263 & $124(46.8)$ & $281(53.0)$ & 0.099 \\
\hline Hyperlipidemia & $24(9.1)$ & $106(11.8)$ & 0.267 & $24(9.1)$ & $67(12.6)$ & 0.156 \\
\hline Family history of CAD & $207(78.1)$ & $661(73.5)$ & 0.148 & $207(78.1)$ & $387(73.2)$ & 0.141 \\
\hline Dominance (\%) & & & 0.033 & & & 0.018 \\
\hline Right- & $249(94.0)$ & $798(88.8)$ & - & $249(94.0)$ & $466(87.9)$ & - \\
\hline Co- & $4(1.5)$ & $27(3.0)$ & - & $4(1.5)$ & $21(4.0)$ & - \\
\hline Left- & $12(4.5)$ & $74(8.2)$ & - & $12(4.5)$ & $43(8.1)$ & - \\
\hline
\end{tabular}

Results are presented as mean \pm standard deviation or $\mathrm{n}(\%)$. The $P$ values represent the difference between inferior $\mathrm{Ml}$ and control. CAD coronary artery disease; 95\% Cl 95\% confidence interval, $M I$ myocardial infarction, OR odds ratio, SBP systolic blood pressure

Table 2 Coronary angiography results of acute inferior $\mathrm{Ml}$

\begin{tabular}{|c|c|c|c|}
\hline Clinical variables & RD group $(n=249)$ & $\mathrm{LD}+$ Co group $(n=16)$ & $P$ value \\
\hline Age (years) & $58.6 \pm 11.6$ & $60.8 \pm 8.5$ & 0.350 \\
\hline Male gender, $\mathrm{n}(\%)$ & $218(87.6)$ & $13(81.3)$ & 0.730 \\
\hline Diabetes Mellitus, n (\%) & $59(23.7)$ & $2(12.5)$ & 0.469 \\
\hline Hypertension, $\mathrm{n}(\%)$ & $118(47.4)$ & $6(37.5)$ & 0.442 \\
\hline Current smoking, n (\%) & $157(63.1)$ & $11(68.8)$ & 0.647 \\
\hline Hyperlipidemia, n (\%) & $19(7.6)$ & $5(31.3)$ & 0.006 \\
\hline Family history of CAD, n (\%) & $195(78.3)$ & $12(75.0)$ & 1.000 \\
\hline \multicolumn{4}{|l|}{ Killip classification, n (\%) } \\
\hline Classl & $63(25.3)$ & $8(50.0)$ & 0.061 \\
\hline Classill & $25(4.0)$ & $2(12.5)$ & 1.000 \\
\hline Classill & $2(1.6)$ & $0(0)$ & 1.000 \\
\hline ClassIV & $5(2.0)$ & $1(6.3)$ & 0.314 \\
\hline \multicolumn{4}{|l|}{ Significant stenosis location, n (\%) } \\
\hline LM & $29(11.6)$ & $3(18.8)$ & 0.653 \\
\hline LAD & $189(75.9)$ & $12(75.0)$ & 1.000 \\
\hline RCA & $206(82.7)$ & $10(62.5)$ & 0.091 \\
\hline LCX & $181(72.7)$ & $14(87.5)$ & 0.313 \\
\hline $\mathrm{OM}$ & $52(20.9)$ & $2(12.5)$ & 0.626 \\
\hline Diagonal branch & $85(34.1)$ & $2(12.5)$ & 0.074 \\
\hline Septal artery & $2(0.8)$ & $0(0)$ & 1.000 \\
\hline \multicolumn{4}{|l|}{ Coronary artery stenosis, $\mathrm{n}(\%)$} \\
\hline One vessel disease $(\geq 50 \%)$ & $27(10.8)$ & $1(6.3)$ & 0.873 \\
\hline Two vessel disease $(\geq 50 \%)$ & $52(20.9)$ & $5(31.3)$ & 0.506 \\
\hline Three vessel disease ( $\geq 50 \%)$ & $170(68.3)$ & $10(62.5)$ & 0.632 \\
\hline
\end{tabular}

$C A D$ coronary artery disease, $L A D$ left anterior descending branch, $L C x$ left circumflex branch, $L M$ left main coronary artery, $M I$ myocardial infarction, $O M$ obtuse marginal branch, $R C A$ right coronary artery 
Table 3 Univariate and Multivariate logistic regression analysis for acute inferior MI

\begin{tabular}{|c|c|c|c|c|}
\hline \multirow[t]{2}{*}{ Variable } & \multicolumn{2}{|l|}{$\begin{array}{l}\text { Univariate regression } \\
\text { analysis }\end{array}$} & \multicolumn{2}{|c|}{$\begin{array}{l}\text { Multivariate regression } \\
\text { analysis }\end{array}$} \\
\hline & OR $(95 \%$ Cl) & $P$ & OR $(95 \% C l)$ & $P$ \\
\hline $\begin{array}{l}\text { Right } \\
\text { Dominance }\end{array}$ & $2.137(1.210-3.776)$ & 0.009 & $2.396(1.328-4.321)$ & 0.004 \\
\hline Baseline SBP & $0.998(0.993-1.003)$ & 0.398 & $0.996(0.989-1.002)$ & 0.217 \\
\hline Heart rate & $1.005(0.997-1.013)$ & 0.200 & $1.007(0.998-1.016)$ & 0.145 \\
\hline Smoking & $1.668(1.233-2.257)$ & 0.001 & $2.087(1.460-2.984)$ & $<0.001$ \\
\hline $\begin{array}{l}\text { Diabetes } \\
\text { Mellitus }\end{array}$ & $2.257(1.528-3.333)$ & $<0.001$ & $2.559(1.698-3.856)$ & $<0.001$ \\
\hline Hypertension & $0.779(0.580-1.047)$ & 0.098 & $0.790(0.561-1.113)$ & 0.178 \\
\hline Hyperlipidemia & $0.688(0.421-1.125)$ & 0.136 & $0.685(0.409-1.146)$ & 0.149 \\
\hline $\begin{array}{l}\text { Family history } \\
\text { of } C A D\end{array}$ & $1.319(0.931-1.869)$ & 0.120 & $1.416(0.976-2.054)$ & 0.067 \\
\hline
\end{tabular}

CAD coronary artery disease, $95 \% \mathrm{Cl}$ 95\% confidence interval, $\mathrm{MI}$ myocardial infarction, $O R$ odds ratio, SBP systolic blood pressure

$\geq 70 \mathrm{bpm}$ ), smoking status (current smoker vs. noncurrent smoker), diabetes mellitus (yes vs. no), hypertension (yes vs. no), hyperlipidaemia (yes vs. no), and family history of CAD (yes vs. no) in the subgroup analysis $\left(P_{\text {interaction }}>0.05\right)$, as shown in Table 4.

Table 4 Subgroup analysis of acute inferior Ml according to right dominance

\begin{tabular}{|c|c|c|c|c|}
\hline Subgroup & $O R$ & $95 \% \mathrm{Cl}$ & $P$ value & $P_{\text {interaction }}$ \\
\hline Baseline SBP & & & & 0.676 \\
\hline$<160$ & 2.290 & $1.244-4.216$ & 0.008 & \\
\hline$\geq 160$ & 3.457 & $0.289-41.370$ & 0.327 & \\
\hline Heart rate & & & & 0.525 \\
\hline$<70$ & 3.319 & $1.154-9.547$ & 0.026 & \\
\hline$\geq 70$ & 2.104 & $1.020-4.337$ & 0.044 & \\
\hline Smoking & & & & 0.419 \\
\hline No & 1.757 & $0.610-5.061$ & 0.297 & \\
\hline Yes & 2.849 & $1.390-5.842$ & 0.004 & \\
\hline Diabetes Mellitus & & & & 0.101 \\
\hline No & 1.909 & $1.019-3.577$ & 0.043 & \\
\hline Yes & 8.140 & $1.582-41.882$ & 0.012 & \\
\hline Hypertension & & & & 0.975 \\
\hline No & 2.440 & $1.139-5.228$ & 0.022 & \\
\hline Yes & 2.330 & $0.912-5.952$ & 0.077 & \\
\hline Hyperlipidemia & & & & 0.104 \\
\hline No & 3.477 & $1.747-6.919$ & 0.001 & \\
\hline Yes & 0.593 & $0.126-2.788$ & 0.508 & \\
\hline Family history of $C A D$ & & & & 0.803 \\
\hline No & 2.336 & $0.740-7.380$ & 0.148 & \\
\hline Yes & 2.652 & $1.319-5.329$ & 0.006 & \\
\hline
\end{tabular}

CAD coronary artery disease, $95 \% \mathrm{Cl} 95 \%$ confidence interval, $\mathrm{Ml}$ myocardial infarction, $O R$ odds ratio, SBP systolic blood pressure

\section{Discussion}

Previous studies have demonstrated a close link between left coronary artery dominance and ACS or significant CAD [23-25]. Left dominance has been identified as a predictor of non-fatal MI and all-cause mortality in patients with significant CAD [13]. Besides, Goldberg et al. [10] reported that patients with ACS and left dominance have a higher long-term mortality, whereas Veltman et al. found that those with a left dominant coronary artery system are associated with a significantly increased risk of 30-day mortality [22]. Despite these findings, the effect of right dominant anatomy on CAD has not attracted enough attention. Our findings indicated that right dominant coronary system is an important predictor of acute inferior MI occurrence after adjusting for confounding factors. This discovery suggests that the assessment of coronary artery dominance may serve as a tool to evaluate the risk stratification of acute inferior MI in clinics.

The pattern of coronary artery dominance was diagnosed according to whether the PDA originates from the RCA, LCx, or both sides, using CAG or computed tomography coronary angiography [26]. The proportion of right, left, and balanced dominance has been reported to be $70-86 \%, 8-13 \%$, and $4-18 \%$, respectively $[8,25,27,28]$. In the present study, right dominance $(94.0 \%$ vs. $87.9 \%)$, left dominance $(4.5 \%$ vs. $8.1 \%)$, and co-dominance $(1.5 \%$ vs. $4.0 \%)$ were statistically different between patients with acute inferior MI and the controls. These results demonstrate that patients with acute inferior MI are more likely to have a right dominant coronary system.

The literature review showed that coronary blood flow of the RCA was $150 \%$ higher in patients with right coronary dominance than in those with left dominance, which indicated more shear stress on endothelial cells in the RCA [7]. Our unpublished data, which contained 2225 patients with CAD who underwent angiography, showed that right dominant anatomy tends to be associated with RCA stenosis and multivessel coronary vascular atherosclerosis. Other studies with a large number of patients also supported that those with right dominance have a significantly higher prevalence of RCA stenosis and multivessel disease [13, 14, 29]. In the present study, compared to patients with left dominance and co-dominance, those with right dominance tended to have more significant stenosis of the RCA ( $82.7 \%$ vs. $62.5 \%)$. Moreover, acute inferior MI usually results from occlusion of the RCA or LCx, and it is occasionally caused by the culprit lesion of the left anterior descending artery. Therefore, we hypothesised that the RCA of patients with right dominant anatomy may sustain more vascular endothelial injury due to higher myocardial perfusion. Subsequently, endothelial dysfunction leads to RCA atherosclerosis and further induces the occurrence of acute inferior MI. 
Furthermore, we found that patients with acute inferior MI complicating posterior MI were more likely to have left dominance and co-dominance. The left ventricular posterior wall was usually supplied by the distal end of the LCx, and coronary blood flow of the LCx is $83 \%$ higher in patients with left dominance than in those with right dominance [7]. Thus, this phenomenon is probably due to different myocardial perfusion among the right, left, or co-dominance, and it may further result in a series of pathological changes. The exact mechanism is worth exploring in our further study.

The present study has several potential limitations. First, the data were obtained retrospectively from an existing CAG database, so the outcomes of patients were unavailable. Second, the study population was relatively small, which led to a smaller group of individuals with left dominance and co-dominance. Third, the findings were based on a Northern Chinese population; thus, a similar study should be performed in a different ethnic group. Finally, to improve the quality of evidence, a prospective, multi-centre cohort will be carried out to explore the relationship between the coronary dominance and MI, short-term and long-term outcomes.

\section{Conclusions}

In conclusion, patients with right coronary artery dominance had a higher occurrence of acute inferior MI compared with left dominance and co-dominance. Right coronary dominance may play a disadvantageous role in the incidence of acute inferior MI.

\section{Abbreviations}

ACS: Acute coronary syndrome; CAD: Coronary artery disease; CAG: Coronary angiography; Cl: 95\% confidence interval; LCX: Left circumflex coronary artery; MI: Acute myocardial infarction; OR: Odds ratio; PDA: Posterior descending artery; RCA: Right coronary artery; SBP: Systolic blood pressure

\section{Acknowledgements}

Not applicable.

\section{Funding}

The study was supported by the National Natural Science Foundation of China (81670049 and 81770057) and the National Key R\&D Program in Shaanxi Province (2017SF-059). The funding Organizations were not involved in the design of the study and collection, analysis, and interpretation of data and in writing the manuscript.

\section{Availability of data and materials}

The datasets used and/or analyzed during the current study are available from the corresponding author on reasonable request.

\section{Authors' contributions}

XCW made a literature review and put forward research hypotheses. LW, XCW, $J M L$ and DS were responsible for primary data analysis. YG, JJZ, RHL, TW and GY were responsible for interpretation of the results. All authors ( $L W, J M L, Y G, J J Z$, RHL, DS, TW, GY, XCW) contributed to the writing of the first draft of the manuscript, and all authors read and approved the final manuscript.

\section{Ethics approval and consent to participate}

The study protocol was approved by the Ethics Committee of the second affiliated hospital of Xi'an Jiaotong university. All participants read the purpose statement of the investigation, and each participant provided written informed consent.

\section{Consent for publication}

Not applicable.

\section{Competing interests}

The authors declare that they have no competing interests.

\section{Publisher's Note}

Springer Nature remains neutral with regard to jurisdictional claims in published maps and institutional affiliations.

\section{Author details}

${ }^{1}$ Department of Critical Care Medicine, the Second Affiliated Hospital of Xi'an Jiaotong University, Xi'an, China. ${ }^{2}$ Department of Cardiology, the Second Affiliated Hospital of Xi'an Jiaotong University, Xi'an, China. ${ }^{3}$ Department of Cardiology, Xi'an Children's Hospital, Xi'an, China. ${ }^{4}$ Department of Cardiology, Shaanxi Provincial People's Hospital, Xi'an, China.

Received: 15 August 2018 Accepted: 23 January 2019

Published online: 04 February 2019

References

1. Reed GW, Rossi JE, Cannon CP. Acute myocardial infarction. Lancet. 2017; 389(10065):197-210.

2. Heusch G, Gersh BJ. The pathophysiology of acute myocardial infarction and strategies of protection beyond reperfusion: a continual challenge. Eur Heart J. 2017:38(11):774-84.

3. Yusuf $S$, Hawken S, Ounpuu S, Dans T, Avezum A, Lanas F, McQueen M, Budaj A, Pais P, Varigos J, et al. Effect of potentially modifiable risk factors associated with myocardial infarction in 52 countries (the INTERHEART study): case-control study. Lancet. 2004;364(9438):937-52.

4. Mehta LS, Beckie TM, DeVon HA, Grines CL, Krumholz HM, Johnson MN Lindley KJ, Vaccarino V, Wang TY, Watson KE, et al. Acute myocardial infarction in women: a scientific statement from the American Heart Association. Circulation. 2016;133(9):916-47.

5. Berger PB, Ryan TJ. Inferior myocardial infarction. High-risk subgroups. Circulation. 1990;81(2):401-11.

6. Sakamoto S, Takahashi S, Coskun AU, Papafaklis MI, Takahashi A, Saito S, Stone PH, Feldman CL. Relation of distribution of coronary blood flow volume to coronary artery dominance. Am J Cardiol. 2013;111(10):1420-4.

7. Mynard JP, Smolich JJ. Influence of anatomical dominance and hypertension on coronary conduit arterial and microcirculatory flow patterns: a multiscale modeling study. Am J Phys Heart Circ Phys. 2016;311(1):H11-23.

8. Knaapen M, Koch AH, Koch C, Koch KT, Li X, van Rooij PC, Tijssen JG, Peters RJ, van der Wal AC, Damman P, et al. Prevalence of left and balanced coronary arterial dominance decreases with increasing age of patients at autopsy. A postmortem coronary angiograms study. Cardiovasc Pathol. 2013;22(1):49-53.

9. Eren S, Bayram E, Fil F, Koplay M, Sirvanci M, Duran C, Sagsoz ME, Diyarbakir S, Okur A, Kantarci M. An investigation of the association between coronary artery dominance and coronary artery variations with coronary arterial disease by multidetector computed tomographic coronary angiography. J Comput Assist Tomogr. 2008;32(6):929-33.

10. Goldberg A, Southern DA, Galbraith PD, Traboulsi M, Knudtson ML, Ghali WA. Coronary dominance and prognosis of patients with acute coronary syndrome. Am Heart J. 2007;154(6):1116-22.

11. Cademartiri F, La Grutta L, Malago R, Alberghina F, Meijboom WB, Pugliese F, Maffei E, Palumbo AA, Aldrovandi A, Fusaro M, et al. Prevalence of anatomical variants and coronary anomalies in 543 consecutive patients studied with 64slice CT coronary angiography. Eur Radiol. 2008;18(4):781-91.

12. Kuno T, Numasawa Y, Miyata H, Takahashi T, Sueyoshi K, Ohki T, Negishi K Kawamura A, Kohsaka S, Fukuda K. Impact of coronary dominance on inhospital outcomes after percutaneous coronary intervention in patients with acute coronary syndrome. PLoS One. 2013;8(8):e72672.

13. Veltman CE, de Graaf FR, Schuijf JD, van Werkhoven JM, Jukema JW Kaufmann PA, Pazhenkottil AP, Kroft LJ, Boersma E, Bax JJ, et al. Prognostic 
value of coronary vessel dominance in relation to significant coronary artery disease determined with non-invasive computed tomography coronary angiography. Eur Heart J. 2012;33(11):1367-77.

14. Parikh NI, Honeycutt EF, Roe MT, Neely M, Rosenthal EJ, Mittleman MA Carrozza JP Jr, Ho KK. Left and codominant coronary artery circulations are associated with higher in-hospital mortality among patients undergoing percutaneous coronary intervention for acute coronary syndromes: report from the National Cardiovascular Database Cath Percutaneous Coronary Intervention (CathPCI) registry. Circ Cardiovasc Qual Outcomes. 2012;5(6):775-82.

15. Khan AR, Khan Luni F, Bavishi C, Khan S, Eltahawy EA. Left dominant circulation increases mortality in acute coronary syndrome: a systematic review and meta-analysis of observational studies involving 255,718 patients. Catheter Cardiovasc Interv. 2016;88(2):201-8.

16. Montalescot G, Sechtem U, Achenbach S, Andreotti F, Arden C, Budaj A, Bugiardini R, Crea F, Cuisset T, Di Mario C, et al. 2013 ESC guidelines on the management of stable coronary artery disease: the task force on the management of stable coronary artery disease of the European Society of Cardiology. Eur Heart J. 2013;34(38):2949-3003.

17. Vijan S. Type 2 diabetes. Ann Intern Med. 2010;152(5):ITC31-15 quiz ITC316.

18. Hou X, Qiu J, Chen P, Lu J, Ma X, Weng J, Ji L, Shan Z, Liu J, Tian H, et al. Cigarette smoking is associated with a lower prevalence of newly diagnosed diabetes screened by OGTT than non-smoking in Chinese men with Normal weight. PLoS One. 2016;11(3):e0149234.

19. Joint Committee for Developing Chinese guidelines on Prevention and Treatment of Dyslipidemia in Adults. Chinese guidelines on prevention and treatment of dyslipidemia in adults. Zhonghua Xin Xue Guan Bing Za Zhi. 2007;35(5):390-419.

20. Levine GN, Bates ER, Blankenship JC, Bailey SR, Bittl JA, Cercek B, Chambers CE, Ellis SG, Guyton RA, Hollenberg SM, et al. 2011 ACCF/AHA/SCAl guideline for percutaneous coronary intervention: a report of the American College of Cardiology Foundation/American Heart Association task force on practice guidelines and the Society for Cardiovascular Angiography and Interventions. Circulation. 2011;124(23):e574-651.

21. Pelter MM, Al-Zaiti SS, Carey MG. Coronary artery dominance. Am J Crit Care. 2011;20(5):401-2.

22. Veltman CE, van der Hoeven BL, Hoogslag GE, Boden H, Kharbanda RK, de Graaf MA, Delgado V, van Zwet EW, Schalii MJ, Bax JJ, et al. Influence of coronary vessel dominance on short- and long-term outcome in patients after ST-segment elevation myocardial infarction. Eur Heart J. 2015;36(17):1023-30.

23. Omerbasic E, Hasanovic A, Omerbasic A, Pandur S. Prognostic value of anatomical dominance of coronary circulation in patients with surgical myocardial revascularization. Med Arch. 2015;69(1):6-9.

24. Gebhard C, Fuchs TA, Stehli J, Gransar H, Berman DS, Budoff MJ, Achenbach S, Al-Mallah M, Andreini D, Cademartiri F, et al. Coronary dominance and prognosis in patients undergoing coronary computed tomographic angiography: results from the CONFIRM (COronary CT angiography EvaluatioN for clinical outcomes: an InteRnational multicenter) registry. Eur Heart J Cardiovasc Imaging. 2015;16(8):853-62.

25. Veltman CE, Hoogslag GE, Kharbanda RK, de Graaf MA, van Zwet EW, van der Hoeven BL, Delgado V, Bax JJ, Scholte AJ. Relation between coronary arterial dominance and left ventricular ejection fraction after ST-segment elevation acute myocardial infarction in patients having percutaneous coronary intervention. Am J Cardiol. 2014;114(11):1646-50.

26. Hutchins GM, Nazarian IH, Bulkley BH. Association of left dominant coronary arterial system with congenital bicuspid aortic valve. Am J Cardiol. 1978; 42(1):57-9.

27. Lam MK, Tandjung K, Sen H, Basalus MW, van Houwelingen KG, Stoel MG, Louwerenburg JW, Linssen GC, Said SA, Nienhuis MB, et al. Coronary artery dominance and the risk of adverse clinical events following percutaneous coronary intervention: insights from the prospective, randomised TWENTE trial. Eurolntervention. 2015;11(2):180-7.

28. Makarovic Z, Makarovic S, Bilic-Curcic I. Sex-dependent association between coronary vessel dominance and cardiac syndrome $\mathrm{X}$ : a case-control study. BMC Cardiovasc Disord. 2014;14:142

29. Vasheghani-Farahani A, Kassaian SE, Yaminisharif A, Davoodi G, Salarifar M, Amirzadegan A, Darabian S, Fotouhi A, Sadigh G, Razavi SA, et al. The association between coronary arterial dominancy and extent of coronary artery disease in angiography and paraclinical studies. Clin Anat. 2008;21(6):519-23.

\section{Ready to submit your research? Choose BMC and benefit from}

- fast, convenient online submission

- thorough peer review by experienced researchers in your field

- rapid publication on acceptance

- support for research data, including large and complex data types

- gold Open Access which fosters wider collaboration and increased citations

- maximum visibility for your research: over $100 \mathrm{M}$ website views per year

At BMC, research is always in progress.

Learn more biomedcentral.com/submissions 